\title{
La producción del verosímil historia. El cine en los límites de la conciencia histórica
}

\section{Production of the verisimilar-history. Cinema in the limits of historical consciousness}

\author{
Pablo Aravena Núñez \\ Instituto de Historia y Cs. Sociales \\ Universidad de Valparaíso \\ Universidad Viña del Mar \\ paravena@uvm.cl \\ Para A.A. \\ La vida entra a borbotones apenas uno abre la ventana ... \\ No se la puede contener.
}

\begin{abstract}
Resumen
En el presente texto se constatan algunas estrategias narrativas de lo que se puede denominar "cine posthistórico": reducción de escala, apuesta por lo cotidiano, renuncia al registro épico y un cierto "antihumanismo". Se postula que dicho cine deja sin pensar la contemporaneidad e imposibilita la producción de conciencia histórica.
\end{abstract}

Palabras clave: Posthistoria, vida cotidiana, realismo, conciencia histórica.

\begin{abstract}
In this paper some narrative strategies are identified of what may be termed "post-historical cinema": reduction of scale, partiality for everyday contexts, abandonment of the epic register and a sort of "antihumanism". It is argued that such cinema fails to reflect upon contemporary reality and impedes the development of a historical consciousness.
\end{abstract}

Keywords: Post-history, everyday life, realism, historical consciousness. 
En este breve escrito - que no aspira a ser más que un intento por sistematizar algunas cavilacionesy ponerlas a prueba- quisiera plantear algunas observaciones y problemas que presenta el modo de narrar de un cine que, a falta de otro concepto, podríamos denominar "posthistórico". Un cine que estaría caracterizado en lo fundamental por la reducción de escala, su apuesta por desplegar un relato desde la óptica de los sujetos - o más bien individuos- medios, comunes y corrientes (algo así como el eco de lo que E.P. Thompson llamó, en su crítica al estructuralismo althusseriano, "el hombre de carne y hueso"). Narraciones descolgadas de cualquier gran proceso, pero además desprovistas de toda épica o, más precisamente, con una épica de mínimos (héroes de parroquia o de barrio). Más aún, me arriesgaría a sostener que es un cine caracterizado por una apuesta "antihumanista” en el sentido más elemental, es decir, por su puesta en relieve tanto de la vileza humana como la falta de control de los hombres y mujeres sobre sus propias acciones: no hay proyecto, porque todo proyecto necesariamente se frustra por las bajas pasiones y la incompetencia humana.

Como se hará evidente, mi preocupación no tiene que ver tanto con cómo se procede, en uso de los códigos fílmicos, para producir un "efecto de realidad" que nos persuada y nos haga aceptar lo visto como acaecido o acaecible. Mi preocupación tiene que ver más bien con los alcances derivados de las relaciones entre la alteración de la conciencia histórica moderna y el tipo de producciones fílmicas ya señaladas (lo que se podría extender sin problema a las producciones televisivas).

En particular me interesa plantear cómo los relatos de estos filmes se nos presentan verosímiles. A qué contexto o a la inscripción en qué nuevo (pseudo)metarrelato se debe la producción de tal verosímil. Para finalmente preguntarnos si más bien el cine no está obligado - si quiere ser "un símbolo que nos haga pensar" (Prada, 2008, p. 97) - a jugar en el límite de lo inverosímil, por ejemplo, introduciendo la figura de lo que pasa hoy por "lo ya no" históricamente verosímil.

\section{Conciencia histórica moderna}

Gadamer (2007, p. 41) sostiene que la conciencia histórica es "el privilegio del hombre moderno de tener plenamente conciencia de la historicidad de todo presente y de la relatividad de todas las opiniones", toma de conciencia que "no permanece sin efecto sobre el actuar espiritual de nuestros contemporáneos”. Definición que se corresponde y complementa con la de Raymond Aron cuando sostiene que la conciencia histórica comporta tres elementos específicos:

"la conciencia de una dialéctica entre tradición y libertad, el esfuerzo por captar la realidad o la verdad del pasado [y] el sentimiento de que la sucesión de organizaciones sociales y creaciones humanas a través de los tiempos no 
es cualquiera ni indiferente, que concierne al hombre en lo que este tiene de esencial" (2004, pp. 103-104).

Es ante todo la conciencia de la historicidad de los hombres, o su carácter prometeico: estos no se someten pasivamente al destino, se comprenden condicionados por el pasado, por la tradición, pero no tienen por qué aceptarlo. Y por último la formulación del historiador José Luis Romero (2008, p. 41):

"una conciencia histórica certera puede proveer al hombre de un criterio seguro para la acción; ante el mundo sabrá descubrir los espectros que creados por fuerzas anónimas-, pueden ser destruidos evitando así su peligro; sabrá descubrir las empresas que las generaciones pasadas emprendieron y que es deber suyo proseguir: hacer historia y no dejarla hacer".

Hay aquí dos ideas que se repiten: la dialéctica continuidad-discontinuidad (o tradición y ruptura) y la del hombre como sujeto-agente, creador o productor de novedad, pero no de cualquier novedad, sino de una novedad que se opone, en la misma medida que se debe, a la tradición y que, por lo tanto, la transforma o la refunda (no cualquier evento es histórico). Estas ideas son los dos pilares que sostienen el sentido moderno de la historia, el que actúa como "patrón para la conciencia histórica, es decir para el modo en que entendemos la relación entre pasado, presente y futuro" (Macón, 2012). Los trabajos de Koselleck (1993) y Hartog (2007) han mostrado bien de qué modo el futuro era la categoría preponderante, de modo tal que la temporalidad histórica de la modernidad se caracterizó por el espacio existente entre horizonte de experiencia y horizonte de expectativa. Pero el mismo Hartog ha sostenido que se trata de un régimen de historicidad hoy agotado para devenir en un puro "presentismo", esto es, el acortamiento del espacio entre horizonte de experiencia y horizonte de expectativa, hasta el límite de que este último queda disuelto en el primero. El espacio necesario para el proyecto tiende a desaparecer generando conformismo o malestar.

El porqué de este agotamiento es permanente motivo de discusión. No obstante, ya es un tópico el apelar a ciertos acontecimientos devastadores. Solo indicaremos un par, que han cumplido con la función de minar los dos pilares ya señalados: la presunta absoluta novedad -el carácter inédito- de un mundo postindustrial, interconectado, globalizado, etc. (que se impondría desechando toda estructura previa) y el Holocausto, la bomba atómica y el desastre ecológico (que nos enrostran la perversidad e incompetencia humana). Pero como lo ha señalado Hayden White (2010, p. 130), los eventos son siempre inesperados o devastadores en relación a un contexto, para este caso, en relación al contexto del sentido moderno de la historia. Estallado el sentido, la conciencia histórica pierde su patrón y llegamos precisamente al punto en donde nos encontramos hoy. 


\section{El cine de la posthistoria}

He propuesto esta denominación considerando la caracterización efectuada por Perry Anderson (1997) sobre el postulado de una era posthistórica, que el historiador inglés localiza en el trabajo de Lutz Niethammer (Posthistoire, Hamburgo, 1989. Citado por Anderson), según el cual de allí en adelante:

"con criterio epistemológico, la verdad estriba antes que todo en las experiencias vitales directas $[. .$.$] Aclarar éstas es el primer deber del historiador, quien$ haría bien en evitar toda interpretación estructural amplia, a menos que resulte necesaria como supuesto delimitador. El conocimiento crítico ha de fundarse no en la vana obstrucción propia de los macrorrelatos, sino en los modestos y triviales libros de la gente común, cuyo sentido de libertad y de responsabilidad se constituyen en la única garantía” (p. 11).

En modo alguno postulo algo así como una determinación directa de estos postulados sobre el cine, pero creo que hay una relación estrecha entre estos y la proliferación de una buena cantidad de films (tanto como libros de historia) que poseen en común tanto la reducción de escala (lo cotidiano, el individuo), como una estrategia narrativa centrada en la absoluta aleatoriedad con que se van encontrando los distintos trayectos vitales para dar finalmente como resultado no solo una existencia sin propósito ni autor ("un proceso sin sujeto ni fin"), sino que además "se resuelve en nada", o simplemente en un acabo de mundo. Pienso en filmes de tan distinto origen como Amores perros (Alejandro González Iñárritu, 2000), Ciudad de Dios (Fernando Meirelles y Kátia Lund, 2002), e incluso Snatch. Cerdos y diamantes (Guy Ritchie, 2000).

En estos filmes la producción del verosímil historia (desdeluego con $h$ minúsculas) está asegurado por el registro intimista y por personajes tan impotentes como cualquiera de los espectadores presentes en la sala de cine (¡riesgosa identificación!). De modo mucho más evidente, por ejemplo, cualquiera de nuestros trayectos cotidianos podría ser instalado en un film como Amores perros. La producción del verosímil apelaa la fragilidady precariedad dela vida delas sociedades latinoamericanas de los noventa, lo que desde luego no es negativo en sí, sino en cuanto a los riesgos de autoafirmación que se generan en el contexto de unas sociedades en las que el futuro se halla obturado.

Perfectamente se podría oponer la crítica que el recién fallecido Francisco Fernández Buey hiciera criticando las historias de la vida cotidiana, al tomar distancia de los enfoques historiográficos "micro" y los planteamientos sociológicos en torno a la categoría de "espectro social": de un tiempo a esta parte - dirá Fernández Buey"hacer historia" significaba "comportarse por encima de la media, salirse de lo normal, 
de lo cotidiano”, pero hoy ya no es más así, ese principio que articuló la imaginación histórica desde la Ilustración, pasando por lo historiadores positivistas y llegando hasta Marx y sus herederos, cae junto con otras categorías como la de clase, conciencia, etc., lo que lo lleva a plantear que "con la crisis presente de la cultura socialista -que no hay que confundir con la crisis del marxismo- la identificación de lo histórico con lo excepcional se oscurece" (1993, p. 215).

El recambio de la trama de la gran historia y la épica por la vida cotidiana y los hombres y mujeres "comunes y corrientes" implica un cambio de concepto de la historicidad humana que tendería a trabajar a favor de la hegemonía de turno. Kantianamente: desestimando que los hombres y mujeres emprendan los proyectos trágicos necesarios para construir un mundo con sentido.

Reconocemos en este recambio una ligazón a las "nuevas" tendencias de las ciencias humanas, léase "metodologías cualitativas", apuesta por la experiencia y la subjetividad, por no retomar otros no tan nuevos proyectos utópico-metodológicos como el de "dar voz a los sin voz" (ciertamente necesarios frente a la hegemonía de una historia de las élites y a la carencia de fuentes para iluminar otros segmentos de la sociedad). Pero nuestra inquietud tiene que ver con su pertinencia en las actuales coordenadas culturales.

Tal como sostiene Martin Jay, la interrogante que se impone en este punto es "cuál vida cotidiana, la de quién debemos examinar” (2003, p. 59).

Ciertas corrientes asociadas a la "nueva historia" o a la "historia de la vida cotidiana" han hecho de las experiencias del hombre medio del pasado su objeto privilegiado de estudio. Se trata de personalidades arrojadas a su destino, nada épicas, nada malditas; vidas "oscuras e infortunadas", para usar la expresión de Foucault: "destinadas a no dejar rastro, que en sus desgracias, en sus pasiones, en sus amores y en sus odios, llevan un tono gris y ordinario frente a lo que generalmente es digno de ser narrado" (1990, pp. 178-180).

Pero el salirse de la media, el levantar un proyecto, ya no ético sino político, va siendo hace ya tiempo inverosímil. Lo verosímil es hoy la soledad en la precariedad, lo que tiende a representarse como único posible.

En este punto creo que es pertinente introducir la pregunta que se anunciaba al comienzo. Si el cine no quiere renunciar a ser "un símbolo que nos haga pensar”, ¿no debe acaso jugar en el límite de lo inverosímil? Frente a esta interrogante simplemente citaré al respecto la postura de Pascal Bonitzer (2007, p. 84): "El cine no puede, si quiere ofrecerle algo al público, dejar la realidad tranquila. Debe intervenir y a menudo de manera catastrófica". Y aun agrega en este mismo sentido: "el mal para Einsestein como para Bazin, es el naturalismo, la ilusión de lo natural, la ilusión de lo real". El cine, como una modalidad del pensar, se debe a la interpretación y no a una siempre imposible descripción. 


\section{Referencias bibliográficas}

Anderson, P. (1997). Los fines de la historia. Barcelona: Anagrama.

Aron, R. (2004). Dimensiones de la conciencia histórica. México D.F.: Fondo de Cultura Económica.

Bonitzer, P. (2007). El campo ciego. Ensayos sobre el realismo en el cine. Buenos Aires: Santiago Arcos Editor.

Fernández Buey, F. (1993). Marxismo ehistoria hoy. En Fortinari, M. (Ed.), Problemas actuales de la historia (pp. 211-228). Salamanca: Universidad de Salamanca.

Foucault, M. (1990). La vida de los hombres infames. Madrid: Ediciones La Piqueta. Gadamer, H. (2007). El problema de la conciencia histórica. Madrid: Tecnos.

Hartog, F. (2007). Regímenes de historicidad. México D.F.: Universidad Iberoamericana.

Jay, M. (2003). La crisis de la experiencia en la era postsubjetiva. Santiago de Chile: Ediciones Universidad Diego Portales.

Koselleck, R. (1993). Futuro pasado. Para una semántica de los tiempos históricos. Barcelona: Paidós.

Macón, C. (2012). La conciencia histórica modernista como testación. Extraído el 30 de noviembre de 2012, desde http://www.genocidescholars.org/sites/ default/files/document $\% 09 \% 5$ Bcurrent-page\%3A1\%5D/documents/ IAGS\%202011\%20CECILIA\%20MACON.pdf

Prada, R. (2008). Aguirre la ira de Dios: filme e historia. Revista de la Universidad de México, 51, 97-98.

Romero, J. (2008). La vida histórica. Buenos Aires: Siglo Veintiuno Editores.

White, H. (2010). El evento histórico. En Ficción histórica, historia ficcional y realidad histórica. Buenos Aires: Prometeo. 